\title{
Control of the Sequential Utilization of Glucose and Fructose by Escherichia coli
}

\author{
By B. CLARK* AND W. H. HOLMS \\ Department of Biochemistry, University of Glasgow, Glasgow GI2 $8 Q Q$
}

(Received 28 October 1975; revised 21 March 1976)

SUMM A RY

In Escherichia coli (ATCCI 5224; ML308), glucose and fructose phosphotransferase systems (PT-systems) are constitutive but activities are increased five and Io-fold respectively by aerobic growth on their respective substrates in defined media. In mixtures, glucose is used preferentially and the fructose PT-system activity is kept at its minimum; but, on glucose exhaustion, it overshoots its steady-state level and growth continues on fructose without lag. Cyclic AMP prevents overshoot.

Continuous cultures operating as turbidostats on mixtures of glucose and fructose do not use fructose if sufficient glucose is present to support growth. If less glucose is available, it is all used and sufficient fructose is metabolized concurrently to maintain the growth rate characteristic of glucose.

Both PT-systems are inhibited by hexose phosphates. Presence of homologous substrate specifically sensitizes each PT-system to inactivation by $N$-ethylmaleimide (NEM). Glucose diminishes the ability of fructose to sensitize its PT-system to NEM. This effect parallels the inhibition of fructose utilization by glucose and suggests that glucose denies fructose access to the fructose-specific part of the PT-system.

\section{INTRODUCTION}

Although growth of E. coli (ATCCI5224; ML308) on a mixture of glucose and fructose is not diauxic (Monod, I942), glucose dominates fructose utilization and the sugars are used sequentially (Clark \& Holms, 1974).

Glucose and fructose are translocated by the phosphoenolpyruvate sugar phosphotransferase system (PT-system) (Kundig, Ghosh \& Roseman, 1964) and it would be expected, therefore, that control of utilization would be exerted at the PT-system level. Kornberg (1972, 1973) examined the control of the fructose PT-system by glucose and reported both repression and inhibition. In particular, the use of mutant strains provided convincing evidence that glucose 6-phosphate and fructose 6-phosphate were involved in the catabolite inhibition of fructose PT-system activity. Thus, in a medium containing glucose and fructose, glucose repressed fructose PT-system synthesis and the hexose phosphates inhibited the residual fructose PT-system activity until it was diluted out by growth (Kornberg, 1972, 1973). However, Roseman (1969) suggested that the inhibition of the fructose PTsystem by glucose may involve competition between glucose and fructose for common components of the PT-system, and so the situation is at present unresolved.

In a preliminary communication (Clark \& Holms, 1974), we described the factors which allow $E$. coli ATCCI5224 to utilize gluccse and fructose sequentially without lag. In this paper we present a more detailed study of these factors and a probable mechanism for the inhibition by glucose of the fructose PT-system.

* Present address: Department of Medical Cardiology, Royal Infirmary, Glasgow G4 oSF.

Vol. 95, No. I was issued 22 July 1976 


\section{METHODS}

Organism. The organism used was Escherichia coli ATCCI5224 (ML308) which has the genotype $i^{-} z^{+} y^{+} a^{+}$so that the lac operon is derepressed. In all other respects it was assumed to be wild type.

Batch culture. The organisms were grown in simple defined media at $37^{\circ} \mathrm{C}$ under aerobic conditions (Hamilton \& Holms, 1970). Bacteria were passaged (Holms \& Bennett, I97I) three times on either Io mM-glucose/salts or $10 \mathrm{~mm}$-fructose/salts media, harvested at I I $600 \mathrm{~g}$ and $4{ }^{\circ} \mathrm{C}$ for Io min, stored overnight at $4{ }^{\circ} \mathrm{C}$, resuspended in chilled buffer (40 $\mathrm{mM}^{-} \mathrm{KH}_{2} \mathrm{PO}_{4}$ and $2 \mathrm{~mm}-\mathrm{MgCl}_{2}$, adjusted to $\mathrm{pH} 7$ with $\mathrm{NaOH}$ ) and inoculated into $800 \mathrm{ml}$ sugar/salts medium.

Continuous culture. The growth apparatus was based on the general design of Baker (1968). Medium was pumped from a 201 reservoir to the growth pot, via a $10 \mathrm{ml}$ pipette assembly to measure flow rate, by a Watson-Marlow peristaltic pump type MHRE 200 (Watson-Marlow, Falmouth, Cornwall). The growth pot was a 21 fermenting vessel (Quickfit FV2L; MacFarlane Robson, Glasgow) containing I 1 of stirred culture. The concentrations of all inorganic constituents and the combined concentration of the two carbon sources were in excess of those required to maintain growth. This apparatus was essentially a turbidostat and turbidity was maintained constant $\left(E_{\mathbf{4 2 0}}=0.5\right)$ by adjustments to the dilution pump to keep $\mu=\mu_{\max }$ (Bryson, 1952). The temperature of the culture was maintained at $37^{\circ} \mathrm{C}$ by using a fixed contact thermometer (J. C. Cowlishaws, Manchester $\mathrm{M}_{4} 4 \mathrm{JB}$ ) which operated a $300 \mathrm{~W}$ infrared lamp via a Sunvic electronic relay (AEI type EA4M; J. C. Cowlishaws).

Continuous culture media. Media contained $40 \mathrm{~mm}-\mathrm{KH}_{2} \mathrm{PO}_{4}$ (adjusted to $\mathrm{pH} 7 \cdot 0$ with $\mathrm{NaOH})$, Io mM- $\left(\mathrm{NH}_{4}\right)_{2} \mathrm{SO}_{4}, 2 \mathrm{~mm}-\mathrm{MgSO}_{4}$, trace metals and glucose or fructose at the concentrations indicated in the text. Trace metals were prepared as follows. In $500 \mathrm{ml}$ distilled water were dissolved $50 \mathrm{~g}$ nitrilotriacetic acid (chel NTA), $\mathrm{I} \cdot \mathrm{I} O \mathrm{~g} \mathrm{FeSO}_{4} \cdot 7 \mathrm{H}_{2} \mathrm{O}$,

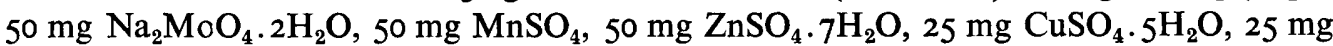
$\mathrm{CoCl}_{2} \cdot 6 \mathrm{H}_{2} \mathrm{O}$. NaOH $(5 \mathrm{M}, 125 \mathrm{ml})$ was added, the $\mathrm{pH}$ value was adjusted to $7 \cdot 0$ with $5 \mathrm{M}-\mathrm{HCl}$, and the solution was made up to $\mathrm{I} 1$ with distilled water.

The phosphate buffer part of the medium in 19.61 distilled water was made up in the apparatus and the whole autoclaved at I2I ${ }^{\circ} \mathrm{C}$. The other components were sterilized separately and $100 \mathrm{ml}$ of each was added aseptically to the reservoir to give a final volume of 201.

Measurement of bacterial growth. Growth was followed turbidimetrically using a doublebeam spectrophotometer (SP800, Pye Unicam) at $420 \mathrm{~nm}$. An extinction of $\mathrm{I} \cdot 0$ was equivalent to $196 \mu \mathrm{g}$ dry wt bacteria/ml for cultures grown on both glucose and fructose.

Unmasking of PT-system activity. Chilled bacterial suspensions (Io $\mathrm{ml}$ ) were blown on to I $00 \mu \mathrm{l}$ of the required concentration of toluene or benzene in ethanolic solution in a chilled I $5 \times 140 \mathrm{~mm}$ test-tube. The mixture was mixed vigorously for $60 \mathrm{~s}$ (toluene) or $70 \mathrm{~s}$ (benzene) on a Whirlimixer (Scientific Instruments, International Inc. (U.K.)) and PT-system activities were determined.

Unmasking of PT-system activities by treatment with an ethanolic solution of toluene (Kornberg \& Reeves, I972 $a, b$ ) was unsatisfactory for $E$. coli ATCCI 5224, since the activity unmasked depended initially on the concentration of toluene (Fig. I). A similar pattern was observed for fructose PT-system activity. Aspiration with oxygen-free nitrogen (100 $\mathrm{ml} \mathrm{min}^{-1}$; $20 \mathrm{~min}$ ) to remove toluene decreased toluene inhibition of both glucose and fructose 


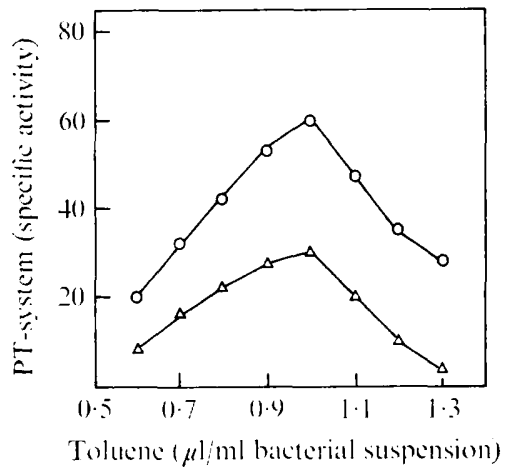

Fig. I

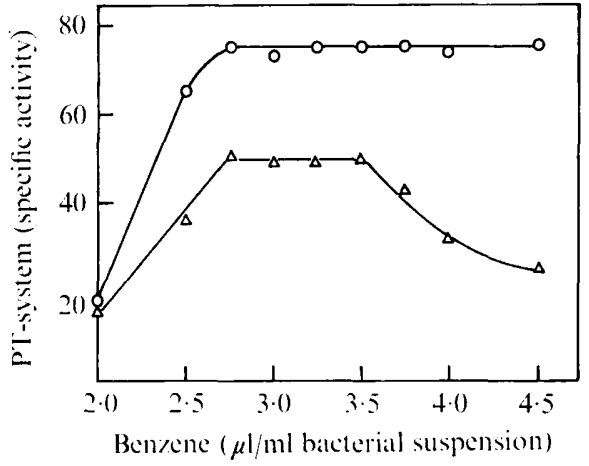

Fig. 2

Fig. I. Unmasking of glucose PT-system activity by toluene. Chilled, washed suspensions of $E$. coli ATCCI 5224 harvested from glucose/salts cultures were treated with various amounts of toluene in ethanolic solution. Glucose PT-system activity was determined (assay I) in these preparations with $(\bigcirc)$ and without $(\triangle)$ removal of toluene by aspiration with oxygen-free nitrogen.

Fig. 2. Unmasking of glucose PT-system activity by benzene. Chilled, washed suspensions of $E$. coli ATCCI 5224 harvested from glucose/salts cultures were treated with various amounts of benzene in ethanolic solution. Glucose PT-system activity was determined (assay I) in these preparations with $(O)$ and without $(\triangle)$ removal of benzene by aspiration with oxygen-free nitrogen.

PT-systems but the activities unmasked by this method were not reproducible for $E$. coli ATCCI5224.

Escherichia coli ATCCI 5224 treated with benzene in ethanol gave reproducible PT-system activities. In non-aspirated preparations, the activity unmasked increased to a maximum with $2.75 \mu \mathrm{l}$ benzene/ml bacterial suspension and then decreased above $3.5 \mu \mathrm{l}$ benzene $/ \mathrm{ml}$ bacterial suspension. Removal of benzene by aspiration with oxygen-free nitrogen gave constant, higher activity from $2.75 \mu \mathrm{l}$ benzene/ml bacterial suspension up to the highest level tested (Fig. 2). A similar pattern was observed for fructose PT-system activity. The following method was therefore used:

Approximately $3 \mathrm{mg}$ dry wt bacteria were removed, chilled in an ice-water slurry, harvested (I $600 \mathrm{~g}$; Io min; $4^{\circ} \mathrm{C}$ ), resuspended in chilled buffer, harvested as before to remove residual sugar, and the pellet was stored on ice. Both glucose and fructose PT-system activities in bacteria so harvested were stable for at least $8 \mathrm{~h}$. Within $7 \mathrm{~h}$, the pellets were resuspended for assay in $15 \mathrm{ml}$ chilled buffer. A portion (4 ml) of each suspension was used for turbidity measurement, and a further portion ( $10 \mathrm{ml}$ ) was blown from a pipette on to $100 \mu \mathrm{l}$ of $35 \%(\mathrm{v} / \mathrm{v})$ benzene in ethanol in a chilled $\mathrm{I} 5 \times \mathrm{I} 40 \mathrm{~mm}$ test-tube and mixed vigorously for $70 \mathrm{~s}$ on a Whirlimixer. The tube was returned to the ice-bath, and the suspension was aspirated with water-saturated oxygen-free nitrogen $\left(100 \mathrm{ml} \mathrm{min}^{-1} ; 20 \mathrm{~min}\right)$ to remove benzene, and assayed immediately for PT-system activity.

Measurement of PT-system activity. PT-system activity was assayed at $27^{\circ} \mathrm{C}$ in plastic cuvettes of I cm light path (no. 40/1010; Walter Sarstedt (U.K.), Leicester LE4 7 LZ) in a final volume of $1.5 \mathrm{ml}$ using a Unicam SP800 double-beam spectrophotometer and Servoscribe chart recorder (Smith's Industries, Wembley, Middlesex).

Glucose PT-system activity (assay I). Assay buffer (0.2 $\mathrm{M}-\mathrm{NaH}_{2} \mathrm{PO}_{4}$ and $2 \mathrm{~mm}-\mathrm{MgSO}_{4}$ adjusted to $\mathrm{pH} 7 \cdot 2$ with $\mathrm{NaOH} ; \mathrm{I} \cdot 4 \mathrm{ml}$ ) containing $0.375 \mu \mathrm{mol}$ NADP, $9 \mu \mathrm{g}$ glucose 6-phosphate dehydrogenase, I5 $\mu \mathrm{mol}$ phosphoenolpyruvate (PEP), and $500 \mu \mathrm{l}$ benzenetreated bacterial suspension, was equilibrated at $27^{\circ} \mathrm{C}$ for $5 \mathrm{~min}$. The reaction was started 


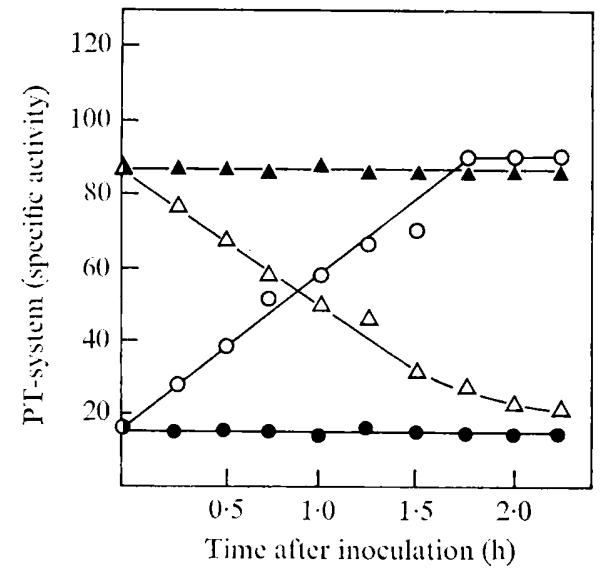

Fig. 3

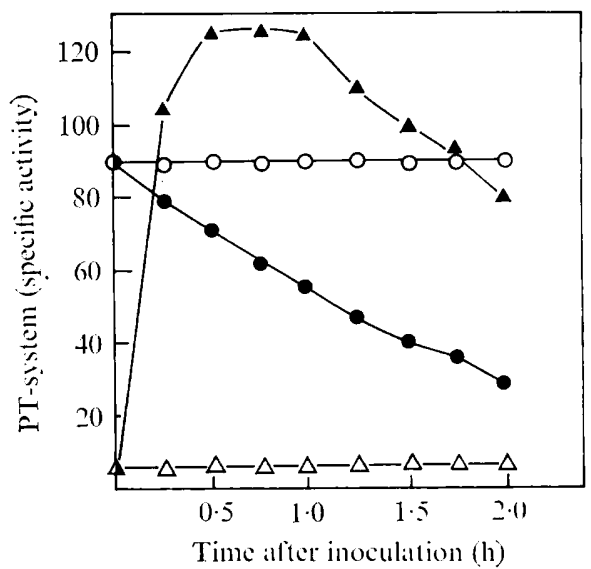

Fig. 4

Fig. 3. Response of PT-systems to changes in growth substrate. Escherichia coli ATCCI5224, previously grown on fructose medium, was inoculated into either $2 \mathrm{~mm}$-glucose $(O, \triangle)$ or $2 \mathrm{~mm}$ fructose $(\boldsymbol{O}, \boldsymbol{\Delta})$ medium. PT-system activities: glucose (assay I), $\bigcirc, \boldsymbol{O}$; fructose (assay 2 ), $\Delta, \Delta$.

Fig. 4. Response of PT-systems to changes in growth substrate. Escherichia coli ATCCI5224, previously grown on glucose medium, was inoculated into either 2 mM-glucose $(O, \triangle)$ or 2 mMfructose $(\mathbf{O}, \Delta)$ medium. PT-system activities: glucose (assay I), $\bigcirc, 0$; fructose (assay 2$), \Delta, \Delta$.

by addition of glucose ( $3 \mu \mathrm{mol}$, I0o $\mu 1)$; controls lacked either PEP or glucose. NADPH production in test and controls was measured as the increase in $E_{340}$ compared with a cuvette containing $500 \mu \mathrm{l}$ benzene-treated bacterial suspension and assay buffer to $\mathrm{I} \cdot 5 \mathrm{ml}$.

Glucose or fructose PT-system activity (assay 2). Ferenci \& Kornberg (1974) reported two fructose PT-systems (in $E$. coli $\mathrm{KI} 2$ strains) that gave fructose I-phosphate and fructose 6-phosphate respectively, but suggested that the PT-system producing fructose 6-phosphate was important only at high fructose concentrations. To avoid the difficulty of measuring the two fructose PT-systems separately, total fructose PT-system activity was assayed by the method below which does not differentiate the two systems. This method was also used for glucose PT-system assay under certain circumstances. Glucose PT-systems gave identical activities by assays $I$ and 2 .

Assay buffer (I.4 ml), containing $0 . \mathrm{I} \mu \mathrm{mol} \mathrm{NADH}, 9 \mu \mathrm{g}$ lactate dehydrogenase, I $5 \mu \mathrm{mol}$ PEP, and $500 \mu \mathrm{l}$ benzene-treated bacterial suspension, was equilibrated at $27^{\circ} \mathrm{C}$ for $5 \mathrm{~min}$. The reaction was started by addition of either glucose or fructose $(3 \mu \mathrm{mol}, 100 \mu \mathrm{l})$ as required; control assays lacked either PEP or sugar. NADH oxidation was measured as the decrease in $E_{340}$ compared with a cuvette containing $500 \mu l$ benzene-treated bacterial suspension, $0 \cdot 1 \mu \mathrm{mol} \mathrm{NADH}$ and assay buffer to $1 \cdot 5 \mathrm{ml}$, to correct for the slight NADH oxidase activity of the bacterial preparations.

Assay results were expressed as mu. enzyme/ml bacterial suspension; I enzyme unit represents the oxidation or reduction of I $\mu \mathrm{mol}$ of NADH or NADP respectively in I min under the assay conditions. Specific activity of PT-system enzymes is expressed as mu. enzyme/mg dry wt bacteria.

Treatment with $N$-ethylmaleimide (NEM). This was done by a modification of the procedure of Haguenauer-Tsapis \& Kepes (1973). After harvesting, the bacteria were washed and resuspended to a density of approximately $200 \mu \mathrm{g}$ dry wt bacteria $/ \mathrm{ml} \mathrm{in} 20 \mathrm{ml}$ chilled buffer. Chilled suspension ( $(3 \mathrm{ml})$ and glucose or fructose $(\mathrm{I} \mathrm{ml}, \mathrm{I} \cdot 5 \mu \mathrm{mol})$ were equilibrated at $27^{\circ} \mathrm{C}$ for $10 \mathrm{~min}$ and NEM $(0.5 \mathrm{ml}, 3 \mu \mathrm{mol})$ was added. After $2 \mathrm{~min}$ further incubation, 
2-mercaptoethanol $(0.5 \mathrm{ml}, 75 \mu \mathrm{mol})$ was added and the mixture was chilled in an ice-water slurry before benzene treatment and assay of PT-system activities.

Measurement of glucose and fructose. A $4 \mathrm{ml}$ sample of culture was blown on to $\mathrm{ml}$ chilled $30 \%(\mathrm{w} / \mathrm{v})$ perchloric acid, mixed and allowed to stand on ice for $10 \mathrm{~min}$; then $3 \mathrm{ml}$ chilled potassium hydroxide (I M) was added to return the $\mathrm{pH}$ to $7 \cdot 0$. The potassium perchlorate precipitate was removed $\left(37000 \mathrm{~g} ; 4^{\circ} \mathrm{C}\right.$; $\left.10 \mathrm{~min}\right)$ and the supernate was decanted and stored at $-20{ }^{\circ} \mathrm{C}$ until assayed.

Glucose was assayed at $\mathrm{pH} 7.2$ in $0.2 \mathrm{M}-\mathrm{NaH}_{2} \mathrm{PO}_{4}, 2$ mM- $\mathrm{MgSO}_{4}, 0.4 \mathrm{~mm}-\mathrm{ATP}, 0.2 \mathrm{~mm}-$ NADP, hexokinase $\left(3 \mu \mathrm{g} \mathrm{ml}^{-1}\right)$, glucose 6-phosphate dehydrogenase $\left(3 \mu \mathrm{g} \mathrm{ml}^{-1}\right)$ in a final volume of $3 \mathrm{ml}$. The assay mixtures were incubated at $27^{\circ} \mathrm{C}$ for $60 \mathrm{~min}$ and $E_{340}$ determined in quartz cuvettes ( $\mathrm{r} \mathrm{cm}$ light path). Fructose was assayed in a similar manner to glucose, with addition of phosphoglucose isomerase $\left(3 \mu \mathrm{g} \mathrm{ml}^{-1}\right)$.

The assays were linear over the range $0-500 \mathrm{nmol}$ glucose or fructose per assay. One mol of glucose or fructose in the assay gave an extinction of $2.07 \times 10^{6}$.

Chemicals. All reagents were Analar or highest purity grade obtainable from BDH, except NADP, phosphoenolpyruvate, lactate dehydrogenase, glucose 6-phosphate dehydrogenase, phosphoglucose isomerase, hexokinase (Boehringer, London); ATP, NADH, cyclic adenosine $3^{\prime}: 5^{\prime}$-monophosphate (free acid), glucose I-phosphate, glucose 6-phosphate, fructose 6-phosphate, fructose I,6-diphosphate, 6-phosphogluconate (Sigma); chloramphenicol (Parke, Davies, Pontypool, Monmouthshire); and oxygen-free nitrogen (British Oxygen Co., Polmadie, Glasgow).

\section{RESULTS AND DISCUSSION}

\section{Response of the PT-systems to changes in growth media}

Fructose-grown bacteria inoculated into fresh fructose/salts medium grew immediately and the initial glucose and fructose PT-system activities remained constant throughout the experiment (Fig. 3); but when bacteria were inoculated into glucose/salts medium, glucose PT-system activity increased and fructose PT-system activity fell (Fig. 3). Growth on glucose was immediate despite the initially low glucose PT-system activity, and the growth rate remained constant over the range of glucose PT-system activities observed.

Glucose-grown bacteria inoculated into glucose/salts medium grew immediately and the initial glucose and fructose PT-system activities remained constant (Fig. 4). Transfer into fructose/salts medium resulted in a very rapid increase in fructose PT-system activity to above the final value (fructose PT-system overshoot) whereas glucose PT-system activity fell (Fig. 4). The fructose PT-system overshoot was prevented by chloramphenicol (0.3 mM), suggesting de novo synthesis of protein rather than activation of a precursor. The specific growth rates $\left(0.9 \mathrm{I} \mathrm{h}^{-1}\right.$ on glucose and $0.73 \mathrm{~h}^{-1}$ on fructose) were constant even when the specific activities of the PT-system varied. The PT-systems must therefore be more efficient relative to their measured activities when these are low. We conclude that, while glucose and fructose PT-systems are constitutive, both respond to the presence of their respective substrates.

\section{Effect of glucose on bacteria growing on fructose}

Glucose (3.5 mM) was added to fructose-grown bacteria inoculated into fresh fructose/salts medium. On addition, the growth rate was stimulated (to $0.9 \mathrm{I} \mathrm{h}^{-1}$ ), synthesis of the fructose PT-system was repressed and that of the glucose PT-system induced (Fig. 5). Fructose utilization slowed down, eventually ceased and did not recommence until nearly all the glucose had been utilized. At glucose exhaustion, the fructose PT-system overshoot occurred, 


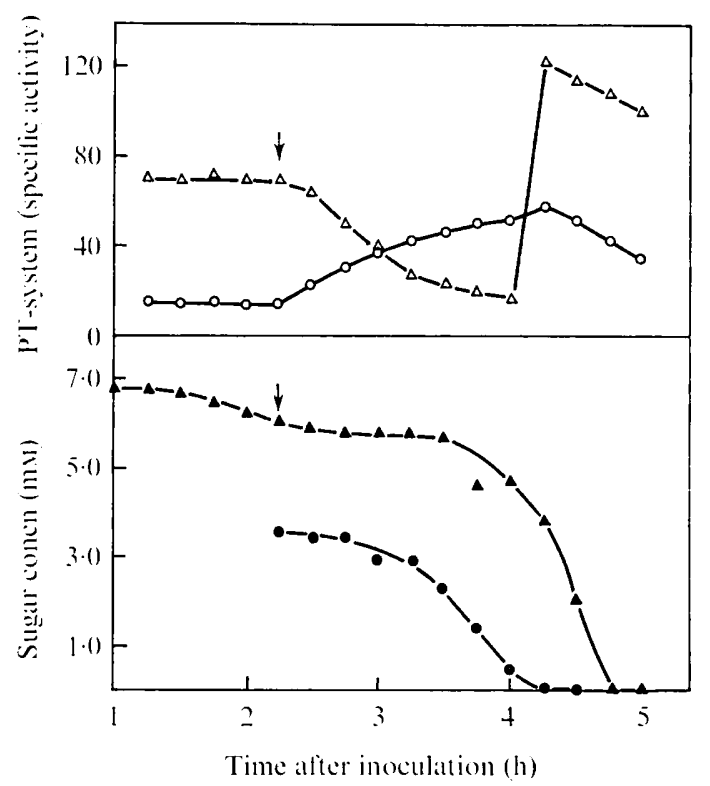

Fig. 5. Effect of glucose addition on PT-system activities and fructose utilization. Escherichia coli ATCCI 5224, previously grown on fructose medium, was inoculated into 7 mm-fructose/salts medium and 3.5 mm-glucose was added at the time indicated by the arrows. PT-system activities: glucose (assay I), $\bigcirc$; fructose (assay 2), $\Delta$. Substrate concentrations: glucose, $\mathbf{O}$; fructose, $\Delta$.

glucose PT-system activity decreased and the growth rate returned to the original value $\left(0 \cdot 73 \mathrm{~h}^{-1}\right)$.

The addition of glucose (Fig. 5) completely inhibited fructose utilization after i 5 to 30 min even though fructose PT-system activity was still high and this inhibition persisted until the glucose was nearly exhausted. The fructose PT-system overshoot (Fig. 5) may be responsible for the absence of diauxie when $E$. coli is growing on glucose and fructose. Such a rapid appearance of the fructose PT-system near glucose exhaustion could enable the bacteria to overcome any remaining glucose inhibition and allow a short period of co-utilization before the glucose was exhausted. We conclude that fructose and glucose are used sequentially because glucose both represses synthesis of the fructose PT-system and inhibits fructose entry into the bacterium. The presence of glucose results in induction of glucose PT-system synthesis and since the slight fall in fructose concentration following glucose addition (Fig. 5) was reproducible, induction of glucose PT-system synthesis is apparently required before glucose can totally inhibit fructose utilization.

\section{Effects of glucose addition to a turbidostat}

Turbidostats were established in which fructose was fed at $3.2 \mathrm{~mm}$, and the turbidity was maintained at $100 \mu \mathrm{g}$ dry wt bacteria/ $\mathrm{ml}$. At this concentration, $\mathrm{I} \cdot 2 \mathrm{mM}$-fructose was utilized for growth $\left(\mu=0.73 \mathrm{~h}^{-1}\right)$ and the excess fructose $(2 \mathrm{~mm})$ washed out in the effluent (Table I). Once glucose additions to the cultures were terminated, these values, and the specific activities for both glucose and fructose PT-systems characteristic of growth on fructose, were re-established. Glucose fed at 3.3 mM, i.e. $2 \mathrm{~mm}$ in excess of requirement, to a turbidostat established on fructose raised the growth rate, induced synthesis of the glucose PT-system, repressed synthesis of the fructose PT-system and inhibited fructose utilization; but, when 


\section{Table I. Effect of glucose on turbidostats of E. coli ATCCI5224 established on fructose}

The general conditions were the same as those for Fig. 6 (100 $\mu \mathrm{g}$ dry wt bacteria $/ \mathrm{ml} ; D$ maintained at $\mu_{\max }$ by adjusting the dilution pump). Fructose $(3.2 \mathrm{~mm})$ medium was fed throughout the experiments. After $20 \mathrm{~h}$ growth on fructose, glucose was added to the feed, at the concentrations shown, for about $10 \mathrm{~h}$ (steady state apparently achieved within $4 \mathrm{~h}$ ), and then withdrawn. Glucose (assay I) and fructose (assay 2) PT-system activities were measured and are expressed as specific activities. The growth rate for fructose alone was $0.73 \mathrm{~h}^{-1}$, and for $3.3 \mathrm{~mm}$-glucose alone was $0.9 \mathrm{I} \mathrm{h}^{-1}$.

\begin{tabular}{|c|c|}
\hline \multicolumn{2}{|c|}{ Glucose (mM) } \\
\hline Feed & Excess \\
\hline $3 \cdot 3$ & $2 \cdot 0$ \\
\hline $1 \cdot 6$ & 0.3 \\
\hline 0.8 & 0 \\
\hline 0.4 & 0 \\
\hline $0 . I$ & 0 \\
\hline
\end{tabular}

$\begin{gathered}\text { Fructose } \\ \text { (mM) }\end{gathered}$
Excess
$3 \cdot 2$
$3 \cdot 2$
$2 \cdot 7$
$2 \cdot 3$
$2 \cdot 0$

$\begin{array}{cc}\text { Glucose } & \text { Fructose } \\ 58 & \text { I2 } \\ 58 & 12 \\ 74 & 40 \\ 70 & 70 \\ 15 & 65\end{array}$

\begin{tabular}{|c|c|c|}
\hline \multicolumn{2}{|c|}{$\begin{array}{l}\text { Fructose PT-system, on } \\
\text { withdrawal of glucose }\end{array}$} & \multirow{2}{*}{$\begin{array}{c}\text { Growth } \\
\text { rate, } \mu \\
\left(\mathrm{h}^{-1}\right)\end{array}$} \\
\hline Maximum & Net overshoot & \\
\hline 105 & 40 & 0.91 \\
\hline 105 & 40 & $0.9 I$ \\
\hline 95 & 30 & $0.9 \mathrm{I}$ \\
\hline 85 & 20 & $0.9 I$ \\
\hline 65 & 0 & 0.83 \\
\hline
\end{tabular}

glucose was withdrawn from the feed, fructose utilization recommenced and there was massive synthesis of fructose PT-system activity which temporarily overshot its normal value (Fig. 6). These data and those from similar experiments are summarized in Table $\mathrm{I}$.

We conclude that glucose represses synthesis of the fructose PT-system and, when it is available in excess of the concentration required to support $\mu_{\max }^{\text {glucose }}$, repression of fructose PT-system synthesis is maximal. When the supply of glucose is limited, the repression of the fructose PT-system is diminished in proportion. In the same way, overshoot in fructose PT-system synthesis on withdrawal of glucose also depends on the previous degree of repression and is greatest when repression has been maximal. Thus the degree of catabolite repression directly determines both fructose PT-system synthesis and the magnitude of the overshoot when repression is relieved. Glucose is the preferred substrate in all circumstances and inhibits fructose utilization to that level which makes up the deficiency in glucose supply.

\section{Effect of cyclic AMP}

Cyclic AMP relieves catabolite repression of the lac operon in this strain under a variety of circumstances (Holms \& Robertson, 1974) and might also affect glucose and fructose PT-system synthesis. When glucose was added to a culture of $E$. coli ATCCI5224 growing exponentially on fructose in the presence of cyclic AMP (Fig. 7), glucose PT-system synthesis was more active and fructose PT-system synthesis less completely repressed than in the absence of cyclic AMP (Fig. 5). Fructose utilization was still completely prevented while glucose remained. The growth rate was also stimulated (from $0.73 \mathrm{~h}^{-1}$ to $0.9 \mathrm{I} \mathrm{h}^{-1}$ ). We conclude that glucose metabolism represses synthesis of both glucose and fructose PT-systems by a mechanism which can be antagonized by cyclic AMP. Even when fructose PT-system activity was four times the repressed value, glucose metabolism completely inhibited fructose utilization. However, cyclic AMP prevented the fructose PT-system overshoot suggesting that this oversynthesis is due to the relief from catabolite repression responding to sudden changes in intracellular cyclic AMP levels on glucose exhaustion (Makman \& Sutherland, I965).

\section{Inhibition of PT-system activity by hexose phosphates}

Kornberg (1972) has obtained convincing evidence that hexose phosphates have an important role in the control of fructose PT-system activity in other strains. The effects of some sugar phosphates on glucose and fructose PT-system activities in benzene-treated cells 

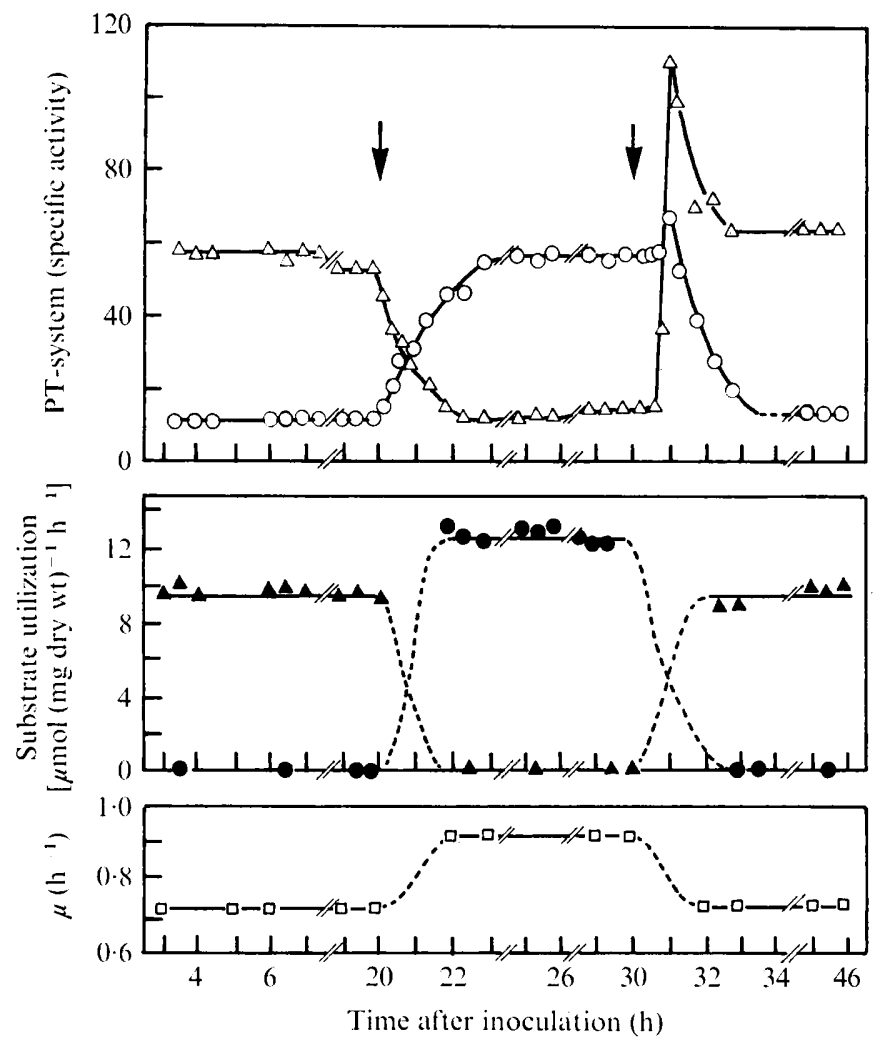

Fig. 6. Effect of glucose on a turbidostat of E. coli ATCCI5224 established on fructose. The culture was inoculated and grown without dilution up to the desired turbidity and then $3.2 \mathrm{~mm}$-fructose was fed continuously for the remainder of the experiment. $3.3 \mathrm{~mm}$-Glucose was added to the feed for Io $\mathrm{h}$ (from $20 \mathrm{~h}$ to $30 \mathrm{~h}$ after inoculation, as indicated by the arrows). Steady-state conditions were apparently achieved after $4 \mathrm{~h}$. Turbidity was maintained constant (100 $\mu \mathrm{g}$ dry wt bacteria/ml) by adjusting the dilution rate $(D)$ so that it equalled the growth rate $\left(\mu_{\max }\right)$. PT-system activities: glucose (assay I), $\bigcirc$; fructose (assay 2), $\triangle$. Substrate utilization: glucose, $\bullet$; fructose, $\boldsymbol{\Delta}$. Specific growth rate, $\square$.

\section{Table 2. Inhibition of glucose and fructose PT-system activities in E. coli ATCCI 5224 by some sugar phosphates}

Samples of E. coli grown on glucose or fructose media were harvested during the exponential growth phase and assayed for glucose (assay 2) and fructose (assay 2) PT-system activities respectively. Assay reactions were started by addition of substrate (glucose or fructose) I min after sugar phosphates $(5 \mathrm{~mm})$ had been added to the otherwise complete mixture. Glucose was assayed by assay 2 to permit study of the effects of glucose 6-phosphate and 6-phosphogluconate. Inhibition is expressed as the specific activity measured relative to that of the control.

\begin{tabular}{|c|c|c|c|c|}
\hline \multirow[b]{2}{*}{$\begin{array}{l}\text { Additions to standard } \\
\text { assay mixture }\end{array}$} & \multicolumn{2}{|c|}{$\begin{array}{l}\text { Glucose PT-system in } \\
\text { glucose-grown bacteria }\end{array}$} & \multicolumn{2}{|c|}{$\begin{array}{l}\text { Fructose PT-system in } \\
\text { fructose-grown bacteria }\end{array}$} \\
\hline & $\begin{array}{l}\text { Specific } \\
\text { activity }\end{array}$ & $\begin{array}{c}\text { Inhibition } \\
(\%)\end{array}$ & $\begin{array}{l}\text { Specific } \\
\text { activity }\end{array}$ & $\begin{array}{l}\text { Inhibition } \\
(\%)\end{array}$ \\
\hline None (control) & $8 I$ & 0 & 71 & o \\
\hline Glucose 1-phosphate & 63 & 22 & 65 & 9 \\
\hline Glucose 6-phosphate & 65 & 20 & 65 & 9 \\
\hline Fructose 6-phosphate & 68 & 16 & 73 & o \\
\hline Fructose 1,6 -diphosphate & 46 & 44 & 22 & 69 \\
\hline 6-Phosphogluconate & 46 & 44 & 35 & $5 \mathrm{I}$ \\
\hline
\end{tabular}




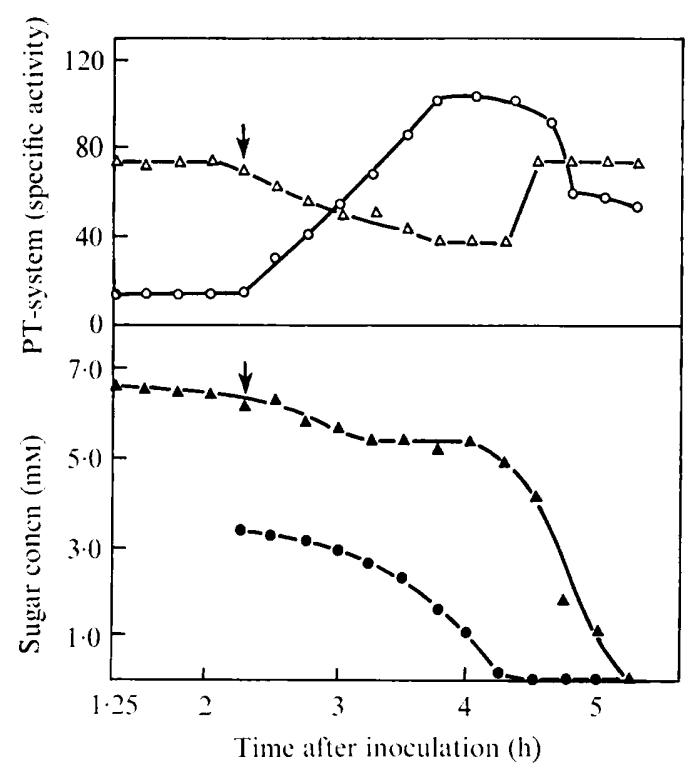

Fig. 7

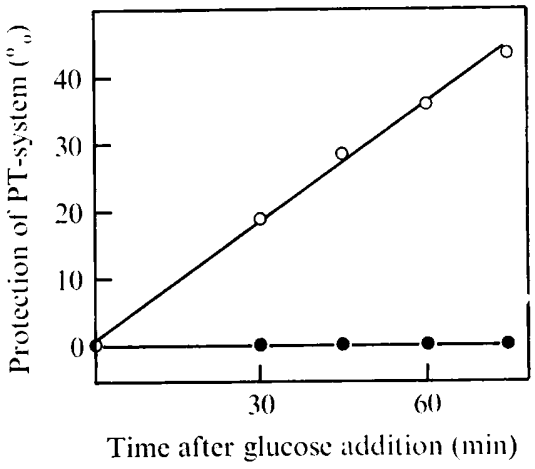

Fig. 8

Fig. 7. Effect of glucose addition to a fructose plus cyclic AMP culture on PT-system activities and fructose utilization. Escherichia coli ATCCI 5224, previously grown on fructose medium, was inoculated into $7 \mathrm{mM}$-fructose/salts medium containing $5 \mathrm{mM}$-cyclic AMP, and $3.5 \mathrm{~mm}$-glucose was added at the time indicated by the arrows. PT-system activities: glucose (assay 1 ), $\bigcirc$; fructose (assay 2), $\triangle$. Substrate concentrations: glucose, $\boldsymbol{O}$; fructose, $\Delta$.

Fig. 8. Interaction of glucose and fructose with their PT-systems after glucose addition to a fructose culture. Escherichia coli ATCCI 5224, previously grown on fructose medium was inoculated into $7 \mathrm{~mm}$-fructose medium and, after $2 \mathrm{~h}$ growth, $3.5 \mathrm{~mm}$-glucose was added. Samples were treated (as described in Methods) with NEM plus 2 mM-glucose or 2 mM-fructose or both. The protection ( $\%)$ of the fructose PT-system $(O)$ by glucose was calculated as:

[Inactivation by (NEM + fructose) - Inactivation by (NEM + fructose + glucose $)] \times$ I00

$$
\text { Inactivation by (NEM+fructose) }
$$

The protection (\%) of the glucose PT-system (O) by fructose was calculated as:

[Inactivation by (NEM+glucose) - Inactivation by (NEM+glucose + fructose)] $\times$ I00

$$
\text { Inactivation by (NEM+glucose) }
$$

of $E$. coli ATCCI5224 were therefore examined (Table 2). For this experiment glucose PT-system activity was determined by assay 2, so that the effects of glucose 6-phosphate and 6-phosphogluconate could be determined. Glucose I-phosphate, glucose 6-phosphate and fructose 6-phosphate inhibited glucose PT-system activity to a greater extent than fructose PT-system activity, unlike results obtained by Kornberg (1972) using a different strain in which these hexose phosphates exerted a strong inhibitory effect on fructose PT-system activity. It is therefore improbable that, at least in E. coli ATCCI5224, these hexose phosphates play a role in establishing glucose dominance. They are more likely to control the overall rate of uptake of glucose and fructose. Fructose 1,6-diphosphate and 6-phosphogluconate strongly inhibited fructose PT-system activity and may have a role in establishing glucose dominance. However, since they also inhibit the glucose PT-system activity (Table 2), they are more likely to control the rate of carbon flux into the cell. 


\section{Table 3. Effect of NEM on PT-system activities}

Escherichia coli ATCCI5224 was grown on glucose or fructose media and harvested during the exponential growth phase. To obtain a preparation in which a high fructose PT-system activity was subject to glucose dominance, a culture grown on 5 mM-glucose plus 5 mM-cyclic AMP medium was harvested and grown in $5 \mathrm{mM}$-fructose medium for $45 \mathrm{~min}$, and then harvested again. The activities after NEM treatment (see Methods) in the absence or presence of 2 mM-glucose, 2 mMfructose or both, are expressed relative (\%) to an untreated control.

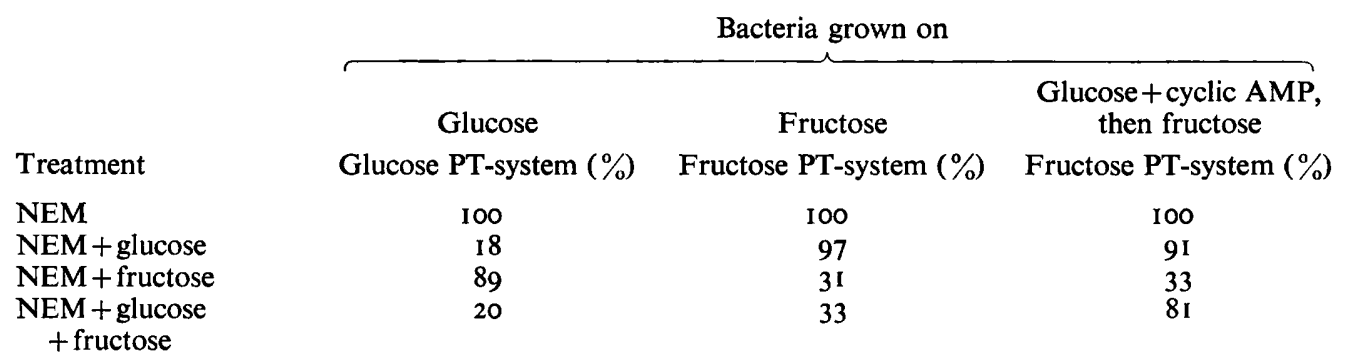

\section{Sensitization of PT-systems to inactivation by $N$-ethylmaleimide}

Haguenauer-Tsapis \& Kepes (I973) found that glucose specifically sensitized the glucose PT-system of $E$. coli KI 2 to attack by $N$-ethylmaleimide. The same effect occurred in our strain (Table 3). The glucose PT-system in glucose-grown bacteria was sensitized to NEM by glucose but much less by fructose. Fructose did not interfere with the action of glucose in a mixture. The fructose PT-system in fructose-grown bacteria was sensitized to NEM by fructose but not by glucose which did not interfere with the action of fructose in a mixture. Bacteria grown in glucose with cyclic AMP had exceptionally high levels of glucose PTsystem activity. When such bacteria were transferred to fructose media, rapid synthesis of fructose PT-system activity ensued, and the bacteria possessed high levels of both fructose and glucose PT-systems; but fructose metabolism was inhibited if glucose was added to the system. Fructose sensitized fructose PT-system activity to NEM but glucose did not and, in a mixture, glucose prevented the sensitization of fructose PT-system activity by fructose (Table 3). About 7I \% of fructose PT-system activity which could be sensitized by fructose was protected by the simultaneous presence of glucose (Table 3).

When glucose was added to cultures of bacteria growing on fructose, the ability of fructose to sensitize the fructose PT-system to NEM progressively diminished (Fig. 8). In contrast, fructose did not affect glucose sensitization of glucose PT-system activity (Fig. 8). We conclude that glucose can interact with the fructose PT-system and that this property is present in those bacteria in which glucose dominates fructose utilization (Table 3) and appears progressively as dominance is established (Figs 5 and 8 ).

Haguenauer-Tsapis \& Kepes (I973) suggested that the sugar-specific enzymes II are the target for NEM and are sensitive to this agent when they are dephosphorylated. In this model, the substrate removes phosphate from its own specific enzyme II during operation of the PT-system and thus causes NEM sensitivity. If the model is correct, it follows that, in those bacteria in which glucose prevents sensitization of the fructose PT-system activity by fructose, the metabolism of glucose prevents the interaction of fructose with its own specific enzyme II. The latter is thus maintained in a phosphorylated form and is therefore insensitive to NEM. This model could also explain the results of Amaral \& Kornberg (1975) with a mutant (DAI) of $E$. coli K2.It in which the inhibition of fructose uptake by either glucose or glucose 6-phosphate is much reduced. This diminution in catabolite inhibition does not 
extend to lactose or glycerol utilization and is specified by a gene which is highly cotransducible with those specifying a fructose-specific component of the PT-system and fructose I-phosphate kinase.

Whatever the detailed mechanism in $E$. coli ATCCI 5224 may be, it seems likely that an interaction between the two PT-systems denies fructose access to its own specific system and reinforces the control of the PT-systems by sugar phosphates. The sum total of these mechanisms permits glucose to dominate fructose utilization. At or near glucose exhaustion, very rapid synthesis of fructose PT-system activity allows a rate of fructose utilization sufficient to support growth without any observable diauxic lag.

Thanks are due to the Science Research Council for a research studentship award to B. C. The investigation was supported in part by grants from the Science Research Council, Medical Research Council and The Royal Society.

\section{REFERENCES}

Amaral, D. \& Kornberg, H. L. (1975). Regulation of fructose uptake by glucose in Escherichia coli. Journal of General Microbiology 90, $157-168$.

BAKER, K. (1968). Low cost continuous culture apparatus. Laboratory Practice 17, 817-824.

BRYSON, V. (1952). Part II. The turbidostatic selector - a device for automatic isolation of bacterial variants. Science, New York 116, 48-51.

Clark, B. \& Holms, W. H. (1974). The relationship of sequential utilization of glucose and fructose to phosphotransferase activities in Escherichia coli ML308. Proceedings of the Society for General Microbiology I, 49.

FERENCI, T. \& KornBerG, H. L. (1974). The role of phosphotransferase-mediated synthesis of fructose-Iphosphate and fructose-6-phosphate in the growth of Escherichia coli on fructose. Proceedings of the Royal Society of London B187, I05-II9.

Haguenauer-TsaPIs, R. \& KePES, A. (1973). Changes in accessibility of the membrane bound transport enzyme glucose phosphotransferase of $E$. coli to protein group reagents in presence of substrate or absence of energy source. Biochemical and Biophysical Research Communications 54, 1335-1341.

Hamilton, I. D. \& Holms, W. H. (1970). Measurement of respiration of micro-organisms during batch culture. Laboratory Practice 19, 795-798.

Holms, W. H. \& BeNNETT, P. M. (197I). Regulation of isocitrate dehydrogenase activity in Escherichia coli on adaptation to acetate. Journal of General Microbiology 65, 57-68.

Holms, W. H. \& RoberTson, A. G. (1974). Control of derepressed $\beta$-galactosidase synthesis in Escherichia coli. Archives of Microbiology 96, 2I-35.

KorNBERG, H. L. (1972). Nature and regulation of hexose uptake by Escherichia coli. In The Molecular Basis of Biological Transport, Miami Winter Symposium, vol. 3, pp. 157-180. Edited by T. S. Woessner, Jr and F. Huijing. New York and London: Academic.

KorNBERG, H. L. (1973). The Leeuwenhoek Lecture 1972. Carbohydrate transport by micro-organisms. Proceedings of the Royal Society of London Br83, 105-123.

KorNBERG, H. L. \& REEVES, R. E. (I972a). Correlation between hexose transport and phosphotransferase activity in Escherichia coli. Biochemical Journal 126, I241-1243.

Kornberg, H. L. \& REEVES, R. E. (1972b). Inducible phosphoenolpyruvate-dependent hexose phosphotransferase activities in Escherichia coli. Biochemical Journal 128, I339-1344.

Kundig, W., Ghosh, S. \& Roseman, S. (1964). Phosphate bound to histidine in a protein as an intermediate in a novel phosphotransferase system. Proceedings of the National Academy of Sciences of the United States of America 52, 1067-1074.

Makman, R. S. \& Sutherland, E. W. (1965). Adenosine $3^{\prime}, 5^{\prime}$-phosphate in Escherichia coli. Journal of Biological Chemistry 240, 1309-1314.

Monod, J. (1942). Recherches sur la Croissances des Cultures Bactériennes. Paris: Hermann and Cie.

Roseman, S. (1969). The transport of carbohydrates by a bacterial phosphotransferase system. Journal of General Physiology 54, 138s-180s. 